\title{
APPLICATION OF ELECTRONIC TONGUE TO DISCRIMINATE WHITE WINES ORIGINATED FROM DIFFERENT REGIONS OF HUNGARY
}

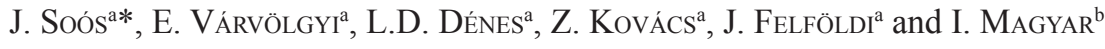

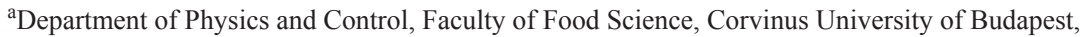 \\ H-1118 Budapest, Somlói út 14-16. Hungary \\ ${ }^{\mathrm{b}}$ Department of Oenology, Faculty of Food Science, Corvinus University of Budapest, \\ H-1118 Budapest, Ménesi út 45. Hungary
}

(Received: 9 April 2014; accepted: 30 May 2014)

\begin{abstract}
In this work, the application of an electronic tongue (ET) based on a specific ion-selective sensor array for discrimination of different white wine types is presented. The electronic tongue equipped with specific sensor array containing seven IFSET sensors was used to analyze wine samples. The obtained ET responses were evaluated using different pattern recognition methods. Principal component analysis (PCA) provides the possibility to identify some initial patterns. Linear discriminant analysis (LDA) was used to build models to separate white wine samples based on wine regions and grape cultivars. The results showed that every group was distinguished from each other with no misclassification error. Furthermore, the sequence of the wine sample groups was similar to the increasing total acidity content. Partial least square (PLS) regression was used to build models for the prediction of the main chemical compositions of the wine samples based on the electronic tongue results. The closest correlation $\left(\mathrm{R}^{2}=0.93\right)$ was found in case of 'total acidity', and the prediction error (RMSEP) was $6.9 \%$. The $\mathrm{pH}$ of the wine samples was predicted with good correlation $\left(\mathrm{R}^{2}=0.89\right)$ but higher prediction error $(\mathrm{RMSEP}=10.71 \%)$ from the electronic tongue results. The ET combining these statistical methods can be applied to determine the origin and variety of the wine samples in easy and quick way.
\end{abstract}

Keywords: electronic tongue, white wine, origin, wine variety

Nowadays, quality assessment is an important topic in food quality control. Therefore, there is a growing demand for an instrument that can measure quality parameters. In this area the electronic tongue (ET) can be a useful tool. The ET notion turned up first in the middle of the nineties. The ET is a system that usually consists of an array of non-specific chemical sensors combined with appropriate data acquisition systems and chemometric tools. During sample assessment the ET sensor array produces an unresolved analytical signal, which correlates with the chemical composition of the sample (Kovícs et al., 2009).

Comprehensive information on the quality and composition of food products has become increasingly important for consumer choice. One of the most important topics is the geographical origin.

It has been found that the electronic tongue is capable to identify Chinese teas (black and green) (He et al., 2009) and Sri Lanka teas (KovÁcs et al., 2010) from different geographical origins. SIPOS and co-workers (2012) correctly classified mineral water samples from the same geographical origin by electronic tongue (100\%). CIOSEK and WRÓBLEWSKI (2008) tested five brands of milk produced in Poland for the classification of milks' origins with the use of a miniaturized potentiometric electronic tongue. The system showed good

* To whom correspondence should be addressed.

Phone: +36-1-482-6205; fax: +36-1-482-6361; e-mail: janos.soos@uni-corvinus.hu

0239-3006/\$20.00 @ 2014 Akadémiai Kiadó, Budapest 
classification abilities towards milks originating from various dairies. Therefore, ET is a useful tool for comparative measurements, e.g. comparison to a reference sample or validating the origin of a sample (KIRSANOv et al., 2012).

The geographical origin and the sensory characteristics are even more important if we are talking about wines. From the point of view of wine quality, the chemical compositions play important roles. Chemical analysis of wine is a mature field of research and almost every type of modern advanced analytical technique has been applied to wine, such as multielemental ICP-MS analysis (KATONA et al., 2012) or ion chromatography coupled to isotope ratio mass spectrometry (GUYON et al., 2013).

Electronic tongues based on voltammetric, potentiometric, or impedance measurements have also been used to distinguish wines with different qualities (ŽERAvík et al., 2009; CETó et al., 2011; Gutiérrez et al., 2011). Potentiometric and voltamperometric ETs have been used to discriminate wine samples according to the grape cultivar and the vintage year and aging stages (RUDNiTSKAYA et al., 2007). These systems have also been expended for multicomponent quantitative analysis of different chemical attributes of interest for the wine industry, such as $\mathrm{pH}$, alcoholic content, organic acids, sulphur dioxide, glycerol, different polyphenolic compounds (LEGIN et al., 2003; Di NATALE et al., 2004). Even the correlation of ET data with sensory descriptors provided by an expert human panel (BuRATTI et al., 2007; Soós et al., 2013) has been also evaluated. However, until now the effect of origin, grape cultivars and chemical components in Hungarian white wines have not been reported.

Therefore the objective of our work was to demonstrate and prove the application potential of the electronic tongue for the evaluation of definite white wine samples. Further aim was to determine the relationship between the results of ET and the main chemical components of the wine samples.

\section{Materials and methods}

\subsection{Materials}

Nine white wine samples were analysed during the experiment (Table 1). The tested wine samples originated from three different Hungarian wine regions: Balaton, Mátra, and Villány. From each wine region there were three different wine samples. These wine samples were produced from different grape cultivar groups: Cserszegi füszeres, Pinot Gris, and Sauvignon Blanc. The wine regions and the wine varieties have been specially selected to be as representative as possible in Hungary. Each wine sample was produced in 2013.

Table 1. The wine regions, the varieties, and the chosen codes

\begin{tabular}{lll}
\hline Wine region & Variety & Code \\
\hline Balaton & Cserszegi füszeres & $\mathrm{BCs}$ \\
Balaton & Pinot Gris & $\mathrm{BPi}$ \\
Balaton & Sauvignon Blanc & $\mathrm{BSa}$ \\
Mátra & Cserszegi füszeres & $\mathrm{MCs}$ \\
Mátra & Pinot Gris & $\mathrm{MPi}$ \\
Mátra & Sauvignon Blanc & $\mathrm{MSa}$ \\
Villány & Cserszegi füszeres & VCs \\
Villány & Pinot Gris & VPi \\
Villány & Sauvignon Blanc & VSa \\
\hline
\end{tabular}




\subsection{Chemical measurement}

The chemical parameters of the wine samples were measured in the accredited laboratory of NÉBIH Borászati Igazgatóság. The total acidity, alcohol, ash content, sugar free extract, density, volatile acidity, and $\mathrm{pH}$ were measured.

\subsection{Electronic tongue measurement}

Alpha ASTREE II (Alpha M.O.S., Toulouse, France) potentiometric electronic tongue equipped with a specific sensor array developed for liquid food analysis was used to measure the white wine samples.

The ET consists of an autosampler containing 16 slots for samples. During the assessment ISFET based potentiometric sensors were used. All measurements were performed with seven sensors (named ZZ, BA, BB, CA, GA, and two HAs according to the producer). These chemical sensors are potentiometric sensors with organic membrane coating that gives each sensor specific sensitivity and selectivity (AlPHA M.O.S., 2003). The sensors were preconditioned before the tests performed by the electronic tongue. The preconditioning includes the actual conditioning and the calibration by the AlphaSoft software. For conditioning we used $0.01 \mathrm{M} \mathrm{HCl}$ solution (recommended by the manufacturer). The conditioning is performed according to AlphaSoft (Standard analysis).

The calibration was performed with the mixed samples containing the nine wines in the same percentage. Each sample was measured in nine replications. All measurements including both conditioning and calibration were performed at room temperature. The detailed description of the instrument was introduced by VÁRVÖLGYI and co-workers (2012).

\subsection{Statistical analysis}

The steady state of ET sensor signals was used as variables for the statistical evaluation. Therefore, the average of the last 10 seconds of each measurement was calculated. This matrix contains the different sample groups with their repetitions (as cases) with the seven electronic tongue sensors (as variables). Outlier detection and sensor selection were applied as the first steps of the data processing.

For the statistical data assessment different statistical evaluation methods were used. Principal component analysis (PCA) was performed to detect patterns and to visualize the results of the electronic tongue tests. PCA is a technique to take linear combinations of the original variables, such that the first principal component has maximum variation, the second principal component has the next most variation subject to being orthogonal to the first, and so on. PCA is frequently applied as a tool to exploratory data analysis. Without losing useful information it is able to reduce multidimensional data sets to lower dimensions for analysis and to treat the outliers (EDWARD et al., 2002).

Stepwise Discriminant Analysis was used to select the sensors for the discrimination. The addition of a single variable is performed regarding the largest improvement in the classification, and the process goes on until the search gets trapped in the first local optimum. In the forward stepwise strategies, the addition of a variable is considered simultaneously based on probability or Fisher criteria (P or F-values). Forward stepwise variable selection evaluates the addition of new variable and removal of previously entered one (BERRUETA et al., 2007).

Linear discriminant analysis (LDA) as a supervised method was applied to evaluate the capability of discrimination of the current system by maximizing the distances between 
classes due to the transformation of variables (VenABLES \& RIPLEY, 2002). Cross-validation (CV) was applied to confirm the LDA. The $2 / 3$ of the data was used in the training set, the other $1 / 3$ was used in the test set in three replicates. Each data appeared at least once as training data and as test data during the replications. The results presented as the average of the three cross validation.

Partial least square (PLS) regression was used to determine relationship between the results of chemical data and electronic tongue tests. The PLS regressions models were tested with leave-one-out (LOO) cross-validation (McLEOD et al., 2009).

The programs R (3.0.1, R Foundation for Statistical Computing, Vienna, Austria) and Statistica 9.0 software (StatSoft, Inc., Tulsa, Oklahoma, USA) were applied for the statistical evaluation and visualization.

\section{Results and discussion}

The results of preliminary data evaluation performed with PCA showed four outliers for each sample. Based on their discrimination ability, six sensors (ZZ, BA, BB, CA, GA, and one of the two HAs) were selected for the further evaluation by Stepwise Discriminant Analysis.

\subsection{Classification by Linear Discriminant Analysis}

The results of LDA performed on ET measurement are shown in Fig.1. The "Sauvignon Blanc of Balaton" sample group showed the highest separation from the other wine samples along Root 1 having $80 \%$ of the variance. The group of the wine samples were located between "Pinot Gris of Mátra" sample group having the lowest 'acid content' $\left(4.5 \mathrm{~g} \mathrm{l}^{-1}\right)$ and "Sauvignon Blanc of Balaton" sample group having the highest 'acid content' $\left(7.4 \mathrm{~g} \mathrm{l}^{-1}\right)$. Consequently, Root 1 follows the order of increasing 'acid content'.

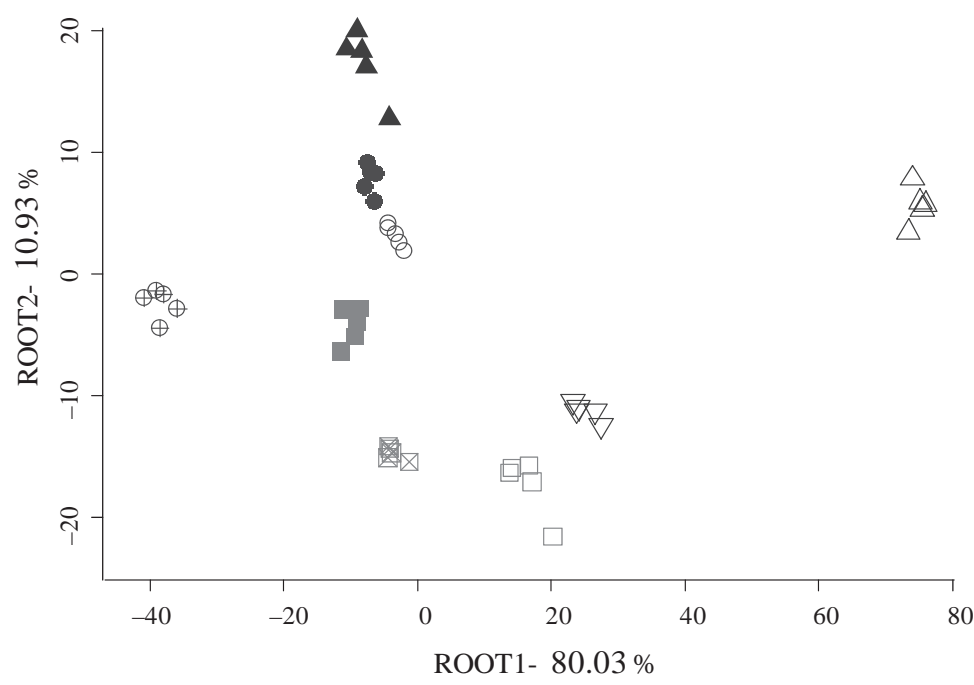

Fig. 1. LDA of the electronic tongue measurements performed with the wine samples. $\square: \mathrm{BCs} ; \bigcirc: \mathrm{BPi} ; \triangle$ : BSa; $\bowtie$ : MCs; $\ominus$ : MPi; $\nabla: \mathrm{MSa} ;$ : VCs; 0 : VPi; $\mathbf{\Delta}$ : VSa 
The corresponding LDA-classification matrix (data not shown), which includes the calibration and the validation (CV), was without any misclassification in the calibration model during the wine regions and the wine types analysis as well. The LDA plots of the discrimination of the wine types are shown in Figure 2. The wine samples made from different kinds of grapes were clearly discriminated along Root 1.

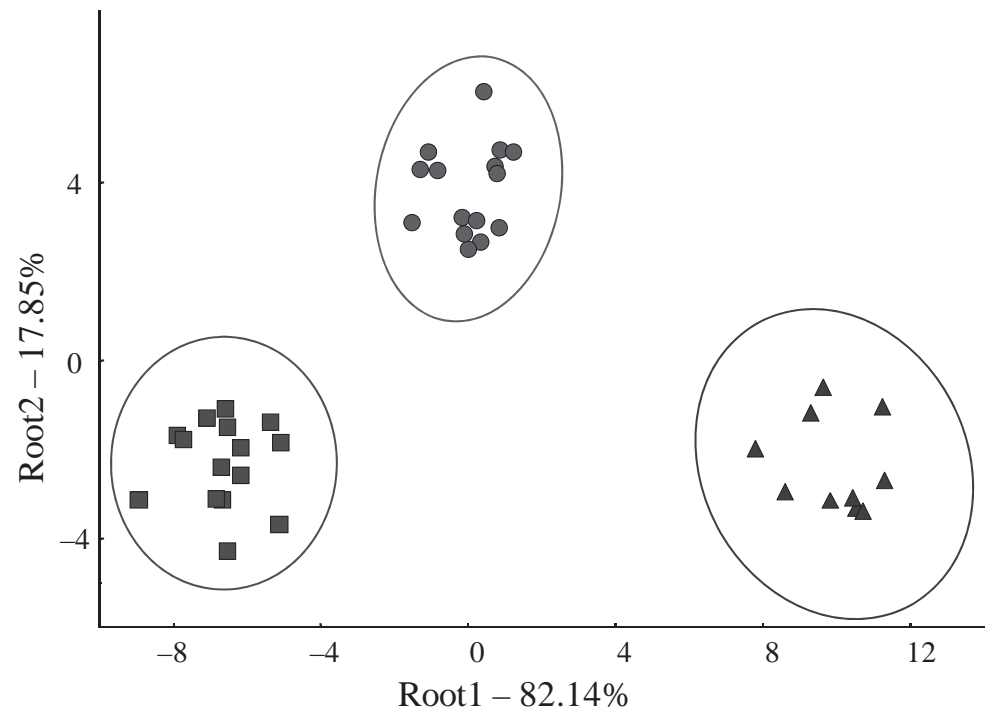

Fig. 2. LDA plots of electronic tongue measurement to discriminate wine types (Ellipses represent the $95 \%$ confidential intervals of the sample groups) $\ldots$ : Cserszegi füszeres; $\odot$ : Pinot Gris; $\Delta$ :Savignon Blanc

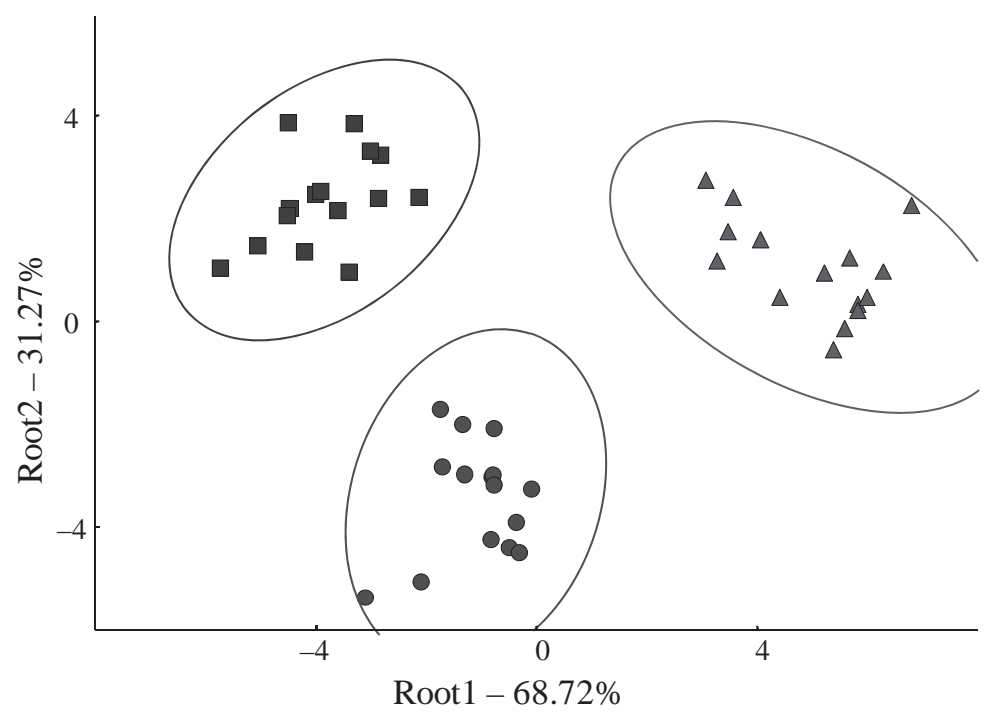

Fig. 3. LDA plots of electronic tongue measurement to discriminate wine region (Ellipses represent the $95 \%$ confidential intervals of the sample groups). ․ : Balaton; 0 : Mátra; $\Delta$ :Villány 
The discrimination of the wine samples from different origin is shown in Figure 3. The three wine regions (Balaton, Mátra, and Villány) were definitely discriminated.

It has been found that the ET is also capable to identify teas (black and green) from different geographical origins by HE and co-workers (2009), PCA (a non-supervised method) was used for the identification. LEGIN and co-workers (2003) ascertained that the ET was also capable of distinguishing wines from different geographical areas, but in the study 23 sensors were used and also PCA was applied to discriminate the wine samples.

\subsection{PLS regression models to predict main chemical attributes of the wine samples}

The determination coefficient and the prediction error values of the PLS regression models are summarised in Table 2. The RMSEP \% values were indicated by the normalized value of the RMSEP.

Table 2. Parameters of ET performance for prediction of chemical attributes

\begin{tabular}{|c|c|c|c|}
\hline & $\mathrm{R}^{2}$ & RMSEP & RMSEP (\%) \\
\hline Total acidity $\left(4.5-7.4 \mathrm{~g} \mathrm{l}^{-1}\right)$ & 0.93 & 0.2 & 6.90 \\
\hline Alcohol (11.18-14.17 vol.\%) & 0.85 & 0.34 & 11.37 \\
\hline Ash content $\left(1.51-2.75 \mathrm{~g}^{-1}\right)$ & 0.88 & 0.13 & 10.48 \\
\hline Density $\left(9887-9952 \mathrm{~g} \mathrm{~m}^{-3}\right.$ ) & 0.7 & 9.2 & 14.15 \\
\hline $\mathrm{pH}(3.1-3.38)$ & 0.89 & 0.03 & 10.71 \\
\hline Sugar free extract $\left(16.3-23.5 \mathrm{~g}^{-1}\right)$ & 0.88 & 0.78 & 10.83 \\
\hline Volatile acidity $\left(0.4-0.5 \mathrm{~g} \mathrm{l}^{-1}\right)$ & 0.4 & 0.02 & 20.00 \\
\hline
\end{tabular}

The closest correlation was found in case of 'total acidity' $\left(\mathrm{R}^{2}=0.93\right)$ (Fig. 4), the prediction error was $\mathrm{RMSEP}=6.9 \%$. Relatively good correlation $\left(\mathrm{R}^{2}>0.85\right)$ was found in 'alcohol and ash content', 'sugar free extract', and 'pH'. KIRSANOv and co-workers (2012) used PLS regression models to predict the total acidity and the $\mathrm{pH}$ values of white wines with a nearly similar correlation $\left(\mathrm{R}_{\text {Total acidity }}^{2}=0.86\right.$ and $\left.\mathrm{R}_{\mathrm{pH}}^{2}=0.95\right)$ and with similar prediction error $\left(\mathrm{RMSEP}_{\text {Total acidity }}=7.64 \%\right.$ and $\left.\mathrm{RMSEP}_{\mathrm{pH}}=6.67 \%\right)$, but they used 25 potentiometric crosssensitive sensors. In case of alcohol prediction, KIRSANOv and co-workers (2012) got worse correlation $\left(\mathrm{R}^{2}=0.7\right)$, but in our study $\mathrm{R}_{\text {alcohol }}^{2}=0.85$ was achieved.

The worst correlation coefficient was found in case of the prediction of 'volatile acid' content. It is not surprising, because ET was designed to measure components dissolved in liquids not to measure volatile substances. 


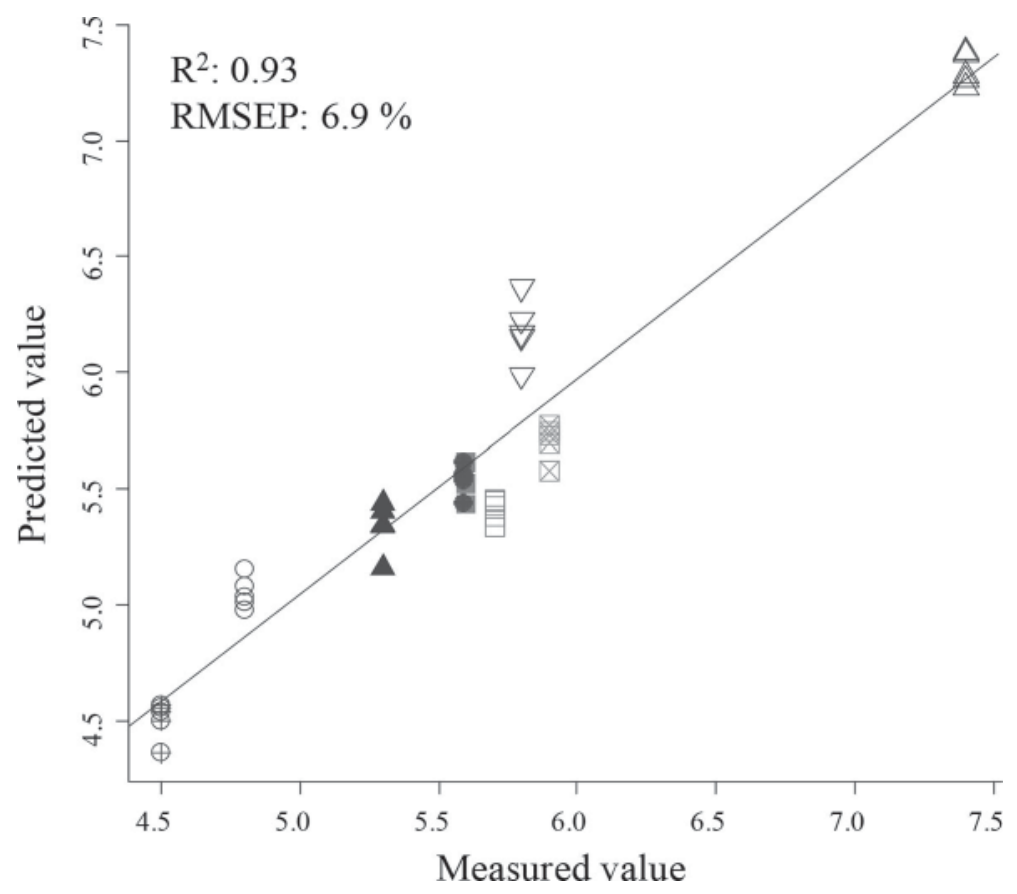

Fig. 4. PLS regression of total acidity from ET measurement. Legends: see Fig.1.

\section{Conclusions}

The electronic tongue is suitable to analyse white wine samples made from different grape types and originated from different wine regions of Hungary. Linear discriminant analysis results performed on the electronic tongue data showed good classification of the wine samples in case of wine region and wine types as well. There was no misclassification error found. Partial least square regression was used to build models for the prediction of the chemical attributes of the wine samples based on the electronic tongue results. The closest correlation was found in case of total acidity $\left(\mathrm{R}^{2}=0.93\right)$, the prediction error was $6.9 \%$ (RMSEP). The $\mathrm{pH}$ was also predicted with good correlation $\left(\mathrm{R}^{2}=0.89\right)$, but higher prediction error $(\mathrm{RMSEP}=10.71 \%$ ) was obtained from the electronic tongue results.

In this study similar results were obtained as in other studies, though after the sensor selection only six sensors (much less than in other studies) were capable to discriminate the wine samples according to the origin and the variety without misclassification, and to predict the chemical attributes with higher correlation.

This work was supported by TÁMOP 4.2.1/B-09/1/KMR/-2010-0005, TÁMOP 4.2.2/B-10/1-2010-0023 and KKD (Kutatási Kiválósági Díj). We are grateful to NÉBIH Borászati Igazgatóság for the wine samples and their chemical results. 


\section{References}

Alpha M.O.S. (2003): $\alpha$ Astree electronic tongue user manual.

Berrueta, L.A., Alonso-Salces, R.M. \& Héberger K. (2007): Supervised pattern recognition in food analysis. J. Chromatogr. A, 1158 (1-2), 196-214.

Buratti, S., Ballabio, D., Benedetti, S. \& Cosio, M.S. (2007): Prediction of Italian red wine sensorial descriptors from electronic nose, electronic tongue and spectrophotometric measurements by means of genetic algorithm regression models. Food Chem., 100, 211-218.

Cetó, X., Gutiérrez, J.M., Moreno-Barón, L., Alegret, S. \& del Valle, M. (2011): Voltammetric electronic tongue in the analysis of cava wines. Electroanal., 23, 72-78.

Ciosek, P. \& WróBlewski, W. (2008): Miniaturized electronic tongue with an integrated reference microelectrode for the recognition of milk samples. Talanta, 76, 548-556.

Di Natale, C., Paolesse, R., Burgio, M., Martinelli, E., Pennazza, G. \& D’Amico, A. (2004): Application of metalloporphyrins-based gas and liquid sensor arrays to the analysis of red wine. Anal. Chim. Acta, 513, 4956.

Edward, R., Conrad, B. \& Selwayan, S. (2002): Multivariate data analysis in electroanalytical chemistry. Electroanal. 14, 1533-1542

Gutiérrez, M., Domingo, C., Vila-Planas, J., Ipatov, A., Capdevila, F., Demming, S., Büttgenbach S., Llobera, A. \& JimÉnEZ-JoRquera, C. (2011): Hybrid electronic tongue for the characterization and quantification of grape variety in red wines. Sensor. Actuator. B-Chem., 156, 695-702.

Guyon, F., Gaillard, L., Brault, A., Gaultier, N., Salagoïty, M.-H., \& Médina, B. (2013): Potential of ion chromatography coupled to isotope ratio mass spectrometry via a liquid interface for beverages authentication. J. Chromatogr. A., 1322, 62-68.

He, W., Hu, X., Zhao, L., Liao, X., Zhang, Y., Zhang, M. \& Wu, J. (2009): Evaluation of Chinese tea by the electronic tongue: Correlation with sensory properties and classification according to geographical origin and grade level. Food Res. Int., 42, 1462-1467.

Katona, R., Abrankó, L. \& StefánKa, Zs. (2012): Comparison of sample preparation techniques for multielemental analysis of wine samples by ICP-MS. Acta Alimentaria, 41 (Suppl. 1), 83-91.

Kirsanov, D., Mednova, O., Vietoris, V., Kilmartin, P.A. \& Legin, A. (2012): Towards reliable estimation of an "electronic tongue" predictive ability from PLS regression models in wine analysis. Talanta, 90, 109-116.

Kovács, Z., Dalmadi, I., Lukács, L., Sipos, L., Szántai-Köhegyi, K., Kókai, Z. \& Fekete, A. (2010): Geographical origin identification of pure Sri Lanka tea infusions with electronic nose, electronic tongue and sensory profile analysis. J. Chemometr., 24(3-4), 121-130.

Kovács, Z., Szöllősi, D. \& Fekete, A. (2009): Application of electronic tongue to soya drink discrimination. Prog. Agric. Eng. Sci., 5, 75-96.

Legin, A., Rudnitskaya, A., Lvova, L., Vlasov, Y., Di Natale, C. \& D’Amico, A. (2003): Evaluation of Italian wine by the electronic tongue: recognition, quantitative analysis and correlation with human sensory perception. Anal. Chim. Acta, 484, 33-44.

Mcleod, G., Clelland, K., Tapp, H., Kemsley, E.K., Wilson, R.H., Poulter, G., Coombs, D. \& Hewitt, C.J. (2009): A comparison of variate pre-selection methods for use in partial least squares regression: A case study on NIR spectroscopy applied to monitoring beer fermentation. J. Food Eng., 90 (2), 300-307.

Rudnitskaya, A., Delgadillo, I., Legin, A., Rocha, S.M., Costa, A.-M. \& Simões, T. (2007): Prediction of the Port wine age using an electronic tongue. Chemometr. Intell. Lab., 88 (1), 125-131.

Sipos, L., Kovács, Z., SÁgi-Kiss, V., Csiki, T., Kókai, Z., Fekete, A. \& Héberger, K. (2012): Discrimination of mineral waters by electronic tongue, sensory evaluation and chemical analysis. Food Chem., 135, 2947-2953.

Soós, J., Kozits, S., Kovács, Z., VÁRvölgyi, E., Szöllősi, D. \& Fekete, A. (2013): Application of electronic tongue to beverages. Acta Alimentaria, 42 (Suppl. 1), 90-98.

VÁrvölgyi, E., Kozits, S., Soós, J., Szöllősi, D., Kovács, Z. \& Fekete, A. (2012): Application of electronic tongue for distinguishing coffee samples and predicting sensory attributes. Prog. Agric. Eng. Sci., 8 (1), $49-63$.

Venables, W.N. \& Ripley, B.D. (2002): Classification. -in: Modern applied statistics with S. Springer, New York, pp. 331-351.

Žeravík, J., Lacina, K., HlavÁČEK, A. \& SkLÁdal, P. (2009): State of the art in the field of electronic and bioelectronic tongues - Towards the analysis of wines. Electroanal., 21, 2509-2520. 